\title{
Obesity-associated distress in Lebanese adolescents: an exploratory look at a large cohort of students
}

\author{
P. Salameh ${ }^{7}$ and B Barbour ${ }^{7}$
}

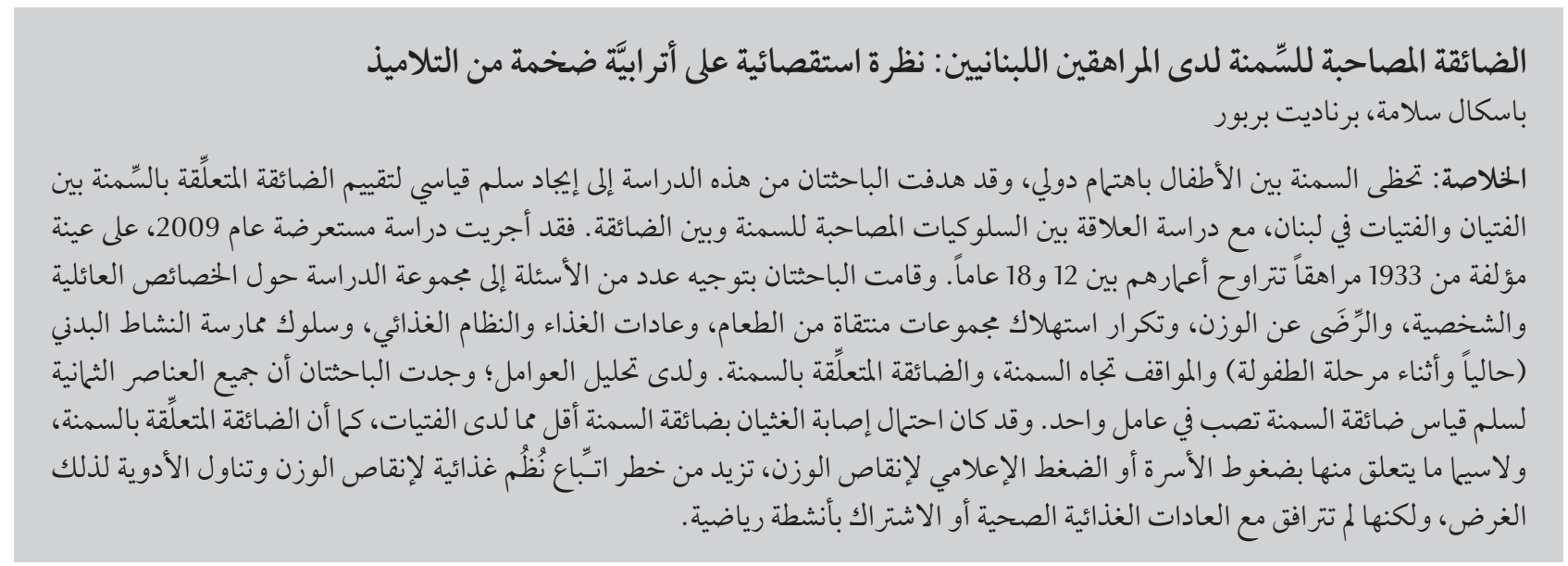

ABSTRACT Childhood obesity has become an international concern. Our objective was to construct a scale for assessing obesity-related distress among Lebanese boys and girls and to study the relationship between obesity-associated behaviours and distress. A cross-sectional study was conducted in 2009 on a sample of 1933 adolescents aged 12-18 years. Questions were asked about personal and family characteristics, satisfaction with weight, frequency of consumption of selected food groups, eating and dieting habits, physical activity behaviour (current and during childhood), attitudes towards obesity, and obesity-related distress. In the factor analysis, all 8 items of the obesity distress scale loaded onto 1 factor. Boys were significantly less likely than girls to be distressed by their obesity. Obesity-related distress, particularly when related to family and media pressure to lose weight, increased the risk of using weight-loss diets and drugs but was not associated with healthy dietary habits or participation in physical activity.

Détresse associée à l'obésité chez des adolescents libanais : étude exploratoire d'un vaste échantillon d'élèves

RÉSUMÉ L'obésité de l'enfant est devenue une préoccupation mondiale. Notre objectif était d'élaborer une échelle de mesure de la détresse associée à l'obésité chez des filles et des garçons libanais et d'étudier la relation entre les comportements associés à l'obésité et la détresse. Une étude transversale a été menée en 2009 sur un échantillon de 1933 adolescents âgés de 12 à 18 ans. Les questions ont porté sur les caractéristiques personnelles et familiales, le niveau de satisfaction par rapport au poids, la fréquence de consommation de certains groupes d'aliments, les habitudes alimentaires et les régimes, le comportement en matière d'activité physique (au moment de l'étude et pendant l'enfance), l'attitude envers l'obésité et la détresse liée à l'obésité. Dans l'analyse factorielle, les huit items de l'échelle de détresse associée à l'obésité étaient regroupés en un seul facteur. Les garçons étaient moins susceptibles d'être en détresse en raison de leur obésité que les filles. Ce type de détresse augmentait le risque de recours à des régimes et médicaments amaigrissants, surtout lorsqu'il était lié à une pression familiale et médiatique pour perdre du poids. Mais il n'était pas associé à des habitudes alimentaires saines, ni à la pratique d'une activité physique. 


\section{Introduction}

Obesity has become the most common chronic disorder in childhood and adolescence in industrialized countries [1]. At the same time contemporary media culture emphasizes thinness and stigmatizes obese persons; this increases the probability of obese young people internalizing negative information about themselves and may cause them to feel psychologically distressed about their physical appearance and self-image [2-4]. Thus, low quality of life [5] and depression, low self-esteem and self-expectations have been identified among many obese teens, especially girls [6]. A disturbed body image may lead to further eating disorders, e.g. binge eating $[3,7]$, even in the absence of overt mental pathology [8].

In a previous study performed on adolescents from Lebanese private schools, we showed that the prevalence of obesity was 2.5 times higher in boys (10.1\%) than in girls (4.2\%). Overweight boys without obesity $(28.8 \%)$ were almost 1.5 times more common than girls $(19.0 \%)[9,10]$. Lebanon is a country where a transition in nutrition habits is taking place [11] and the causes of obesity in adolescence may lie in unhealthy dietary habits and low levels of physical activity [12-18].

To our knowledge, no scale has been validated to specifically assess obesityrelated distress in Lebanon, particularly in adolescents. We therefore carried out an exploratory study of obesity-related factors and distress. We have presented the results relating to correlates of adolescent obesity in another paper [19]. In the present analysis, we aimed to construct a scale for assessing obesity-related distress among Lebanese boys and girls and to study the relationship between obesityassociated behaviours and distress.

\section{Methods}

\section{Study design and sample}

A cross-sectional study was conducted between May and July 2009 on a sample of adolescents aged between 12 and 18 years attending Lebanese schools. We chose this age category because children 12 years old and over are generally able to respond adequately to questionnaires and as Lebanese schools comprise adolescents up to 18 years of age. A convenience sample of 20 schools was chosen from the 5 Lebanese districts: 2 in Beirut, 9 in Mount Lebanon, 3 in North Lebanon, 3 in South Lebanon and 3 in the Bekaa. One school in Beirut refused to participate, while all others agreed to enrol and to distribute a total of 2503 questionnaires. Of these, we obtained 1933 adequately filled questionnaires (77.2\% response rate).

\section{Data collection}

Three researchers were trained to collect the data from students in the required age group from the schools' health registers, in collaboration with the director and/or the school health professional. After explanations about the general objectives of the study, the selected adolescents were asked to complete a questionnaire on the spot, enquiring about baseline characteristics (age, sex, region of residence, height and weight), personal and family characteristics (obesity history) and satisfaction with their weight. Questions were also asked about frequency of consumption of selected food groups, eating and dieting habits, in addition to questions regarding physical activity behaviour (current and during childhood) and attitudes towards obesity. Participants completed the obesity-related distress scale which was developed for this study. Although participation was not mandatory, no students refused to participate since participation was requested by the school directors.

\section{Anthropometric measures}

Body mass index (BMI), calculated as weight in $\mathrm{kg}$ over height in meters squared, was used to evaluate obesity (normal weight, at-risk of obesity and obese) $[20,21]$. Although the WHO standard reference cut-offs can be used [22], we preferred to use the cut-off values taken from the International Obesity Taskforce for BMI of children aged 2-18 years to define obesity and at-risk of obesity (overweight but not yet obese) in order to compared the results with previous work performed in Lebanon $[9,10,19]$. The latter cut-offs for children correspond to the widely used cut-off points of $30 \mathrm{~kg} / \mathrm{m}^{2}$ and 25 $\mathrm{kg} / \mathrm{m} 2$ for adult obesity and overweight [23].

To validate the self-reported measures, height and weight were measured in a randomly selected subsample of 225 adolescents using calibrated balance (Soehnle, sensitivity 500g) and a stadiometer for height measurement (Stanley-Mabo). Measurements were made with the students wearing light indoor clothing and without their shoes. Simple regression equations were generated to validate the self-reported height and weight values; correlation coefficients along with their associated $t$-test were performed. The predicted values were then used as corrected height and weight.

\section{Physical activity behaviour}

To assess levels of physical activity we used a standard questionnaire to measure habitual leisure time sports or recreational activities other than those performed in physical education classes during school. We defined metabolic equivalents (MET) for the energy expenditure above that required for activities of daily living, for activities e.g. bicycling $(\mathrm{MET}=8)$, basketball $(\mathrm{MET}=8)$ and walking for exercise $(\mathrm{MET}=4)$ and lessons e.g. swimming $(\mathrm{MET}=6)$, dance $(\mathrm{MET}=6.5)$ and stretching $(\mathrm{MET}=2.5)$ [24-26]. The physical activity score was computed by multiplying an estimate of the MET for each recorded activity by the weekly frequency with which it was performed and an overall average weekly score was calculated as MET-times per week; a higher score indicated greater activity 
[27]. The physical activity level was then standardized as: standard MET-times/ week $=($ MET-times $/$ week-sample mean)/standard deviation). For descriptive purposes, we classified the physical activity MET-times/week variable into 4 categories: no physical activity $(<-1)$, low $(-1$ to -0.99$)$, moderate $(0-$ to 0.99$)$ and vigorous $(\geq 1)$.

\section{Frequency of selected food groups}

The food frequency questionnaire comprised questions about the frequency of consumption of 8 selected food groups. Foods were selected for the questionnaire if they were commonly consumed by the majority of the Lebanese population: at least once weekly for items and at least once monthly for dishes [28].

For the first 2 groups, dishes were selected if, according to the classification of the SAIN (score of nutritional adequacy of individual foods) and LIM (score of nutrients to be limited) nutrient profiling system $[29,30]$, they were considered as "unhealthy", i.e. had a low SAIN and high LIM or "healthy", i.e. had a high SAIN and low LIM. The selected dished were then classified into 2 classes:

- Lebanese traditional dishes ("healthy"), e.g. Lebanese tabbouleh (bulgur wheat, parsley and tomatoes mixed with lemon and olive oil sauce), yakhnet types (legumes stew), mjaddra (lentil purée), loubieh bzeit (green beans in oil), fattouch (fresh vegetables mixed with toasted bread).

- Fast food dishes ("unhealthy") e.g. mna'ouche bzaatar (Lebanese thyme pizza), man'oucheh bjebneh (Lebanese cheese pizza), hamburger, cheeseburger, Italian pizza and pastas, French fries.

We also added 6 other classes of food that were deemed to be important for adolescents:

- Dairy products, e.g. milk, cheese, yogurt, labneh (white cheese). These food items are frequently consumed with bread in Lebanon for breakfast or dinner [general observation].
- Snack foods: both sweet, e.g. sweets and candies, and salted, e.g. potato chips and popcorn.

- Liquids: e.g. fruit juices (natural or artificial) and carbonated, sweetened soft drinks.

- Vegetables, e.g. tomatoes, cucumber, lettuce, and fruits, e.g. apples, oranges, pears, bananas, grapes. These were the fruits and vegetables most commonly consumed by the Lebanese population and were grouped into one class

\section{Eating habits}

Questions were asked about regular eating habits: the rapidity and timing of eating, meal frequency, eating between meals, plate emptying, and eating during times of psychological distress. Questions were also asked about dieting: being on a weight-loss diet, counting calories, eating "light" food, taking drugs to lose weight, and being urged by the media or family to lose weight.

\section{Obesity-related distress scale construction}

The obesity-related distress scale was designed to cover the dimensions of obesity-related distress and to obtain a multifactorial measurement for the physical, social and psychological axes of obesity-related distress $[24,25]$. A set of items were generated by the authors who are experts in epidemiology and in sociology. The items fell into the categories of emotional functioning (low selfesteem, feeling depressed most of the time, feeling anxious most of the time, suicidal ideation, not loving oneself); physical functioning (difficulty in daily activities, dyspnoea on effort); body image disturbances (avoiding looking in mirrors, avoiding being photographed, difficulty in dressing); sexual problems (difficulty in dating, feeling undesired by persons of the opposite sex); social avoidance (public distress, impaired social life, poor communication with others) and marginalization (being criticized by others, being rejected during games, being teased by others, being disliked by others). A total of 34 items were generated which were reviewed and compared with current internationally used scales $[31,32]$. All items had a 3-point Likert-type response format $(1=$ never, 2 = sometimes, $3=$ yes). The questionnaire was translated into Arabic language by 2 independent Lebanese translators who had expertise in French to Arabic translation. Translation discrepancies were resolved in collaboration with the investigators. The items were then tested on 8 individuals, who did not report any problems in understanding the scale.

This preliminary version of the scale, which included all 34 items, was administered to the sample of 1933 individuals. The scale construction required several steps. Reliability of the score was estimated by computing internal consistency (Cronbach alpha). In addition, the validity of the instrument was tested in 2 different ways. We first conducted a factor analysis by the principal component analysis technique, after checking the sample adequacy for this type of analysis. It would be expected that the item pool would be clustered into several factors referring to the above-mentioned dimensions of obesity-related distress. Factor loadings were retained if higher than 0.35 . We thus eliminated 26 irrelevant items due to low factor loading $(<0.35)$, leaving an 8 -item scale. The sum of these items (score range 8-24) constituted the global score for an individual.

We examined the group difference validity of the construct (i.e. the ability of the instrument to distinguish groups known to differ from one another) by comparing scores on the scale by sex, BMI category (normal weight, at-risk of obesity and obese) and satisfaction with weight (satisfied and not satisfied with weight).

\section{Statistical analysis}

Data entry and analysis were performed using SPSS statistical software, version 13.0. 
The chi-squared test was used to compare percentages of nominal variables between groups (sex and BMI status categories), while Somers' D test was performed for ordinal variables, e.g. food consumption and physical activity frequencies and BMI status. Non-parametric tests were used to compare the distribution of discrete or non-normal variables across categories: Wilcoxon rank sum test to compare between 2 groups and Kruskal-Wallis test to compare between more than 2 groups.

A stepwise descendant multivariate logistic regression was carried out, with obesity-related distress as the dependent variable. Independent variables were all other variables evaluated in this study. Factors taken into account were age, sex, BMI status categories, eating when psychologically distressed, ever being on a weight-loss diet, ever taking drugs to lose weight, urged by the media to lose weight, urged by family to lose weight, and satisfaction with own weight.

In all statistical analyses, $P<0.05$ was considered statistically significant.

\section{Results}

\section{Obesity-related distress scale}

A description of the 8 items in the final version of the obesity-related distress scale is given in Table 1. These were: impaired social life, low self-esteem, difficulty dressing, dyspnoea on effort, difficulty in daily activities, poor communication with others, being criticized by others, and avoiding looking in mirrors. In the factor analysis, all 8 items loaded onto 1 factor, giving 1 dimensional solution for the scale. This factor alone explained $53.1 \%$ of the total variance. The reliability analysis showed a high Cronbach alpha of 0.87 .

Table 1 also shows the frequency of responses to scale items by sex and by BMI category. All items of the scale were significantly different comparing boys and girls, except for the item on avoiding looking in mirrors. When comparing between BMI status categories, significant differences were found for all variables, except for poor communication with others (Table 1).

The total mean obesity distress score was significantly higher for girls than for boys [13.1 (SD 4.7) versus 12.6 (SD 4.7)] $(P=0.002)$. Obese individuals globally had higher mean scores $[13.8$ (SD 4.5)] than individuals at-risk of obesity $[12.7($ SD 4.5)] $(P<0.001)$. Moreover, girls scored significantly higher on obesity-related distress than boys within both the obesity [mean score 16.4 (SD 4.5) versus 13.8 (SD 4.5)] and at-risk of obesity categories [14.1 (SD 4.3) versus 12.7 (SD 4.5)] $(P<0.01)($ Table 2$)$.

\section{Factors associated with obesity-related distress}

\section{Baseline characteristics}

Table 3 shows the mean total scores of respondents on the obesity-related distress scale and the frequency of responses in distressed and non-distressed individuals according to respondents' baseline characteristics. There was significantly more obesity distress in the Bekaa and Beirut regions, in individuals suffering from a disease that favours obesity, in the case of family obesity, in those with a history of childhood obesity and in individuals dissatisfied with their own weight $($ all $P<0.001)$.

\section{Food consumption, eating and diet- ing behaviour}

We found that individuals distressed due to obesity did not have different eating habits than those who are not distressed, except for eating potato chips and popcorn more frequently $(P<0.01)$. In addition, eating more fruits and vegetables and less carbonated soft drinks had a tendency to be related to greater distress, although the results were inconsistent. Consumption of other foods associated with obesity was similar in these 2 categories of people (fast food, Lebanese dishes, fruit juices) $(P>0.05)$ (Table 4$)$.

Obesity-distressed individuals more frequently sought to eat light food, tried to count calories, ate when psychologically distressed and were more encouraged by media publicity to eat food (all $P<0.001)$. Moreover, they had more frequently ever been on diet, ever taken drugs to lose weight and felt urged by the media and their family to lose weight (all $P<0.001)$ (Table 5).

\section{Physical activity behaviour}

In the measure of physical activities, obesity-distressed individuals performed significantly less sports $(P=$ $0.01)$, had a significant trend towards lower number of hours of sport weekly $(P=0.02)$ and had a (borderline) lower level of physical activity $(P=0.06)$ (Table 6).

\section{Multivariate analysis}

In the multivariate analysis, obesityrelated distress was significantly associated with the following variable: urged by family to lose weight, urged by media to lose weight, eating when psychologically distressed and dissatisfaction with own weight (Figure 1).

\section{Discussion}

This study reports the development of an obesity-related distress scale for Lebanese adolescents. Physical, psychological and social items all loaded on a 1-dimensional factor, indicating that obesity in Lebanese adolescents causes distress on all axes concomitantly. This is in contrast with the results of other researchers, who found a multifactorial pattern to obesity-related quality of life $[33,34]$. More research is needed to explore these results. Nevertheless, this scale was able to differentiate between individuals who were obese, at-risk of obesity and normal weight.

In addition, girls were more prone to report obesity-related distress than 


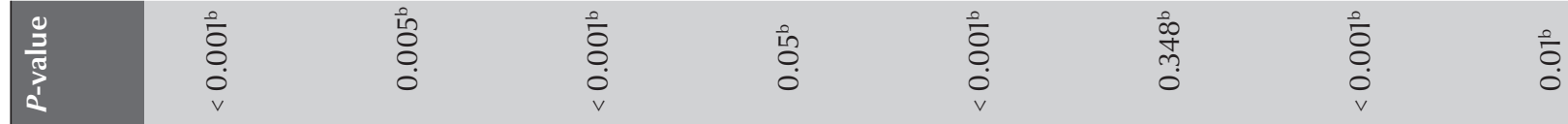

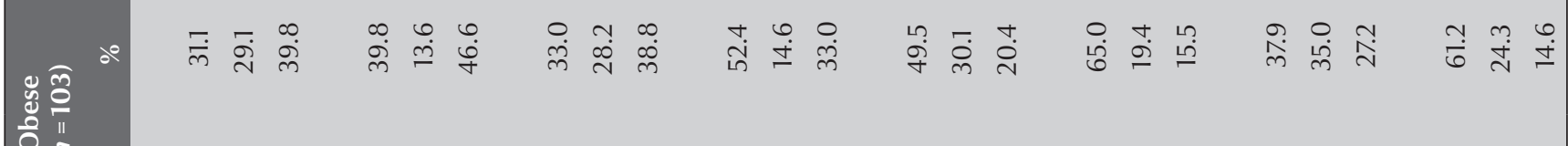

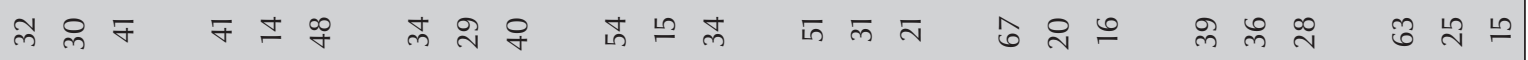

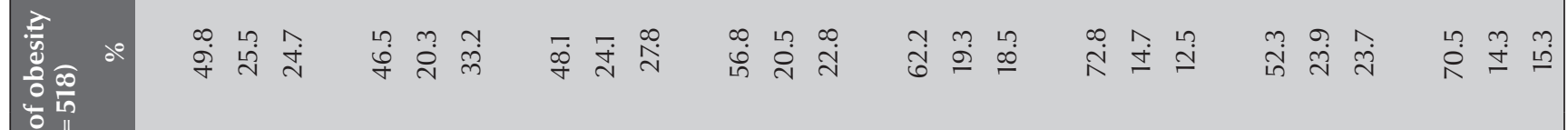

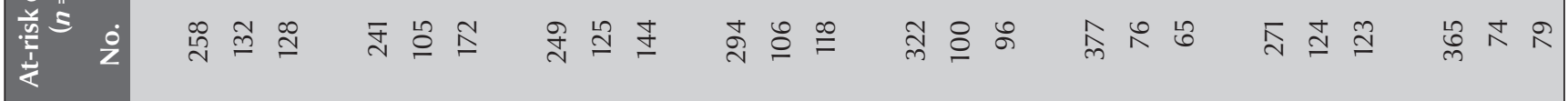

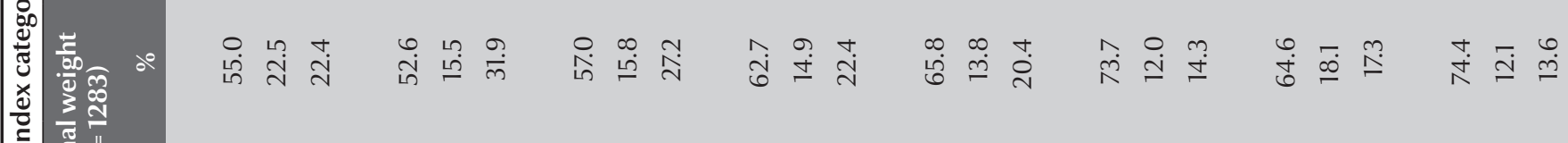

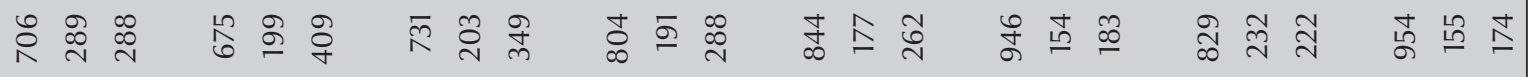

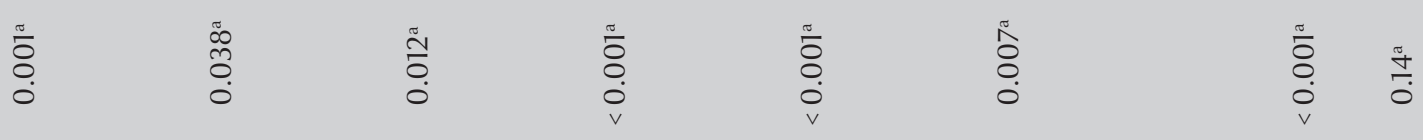
ॠ 我

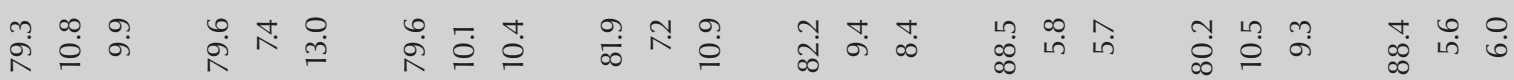

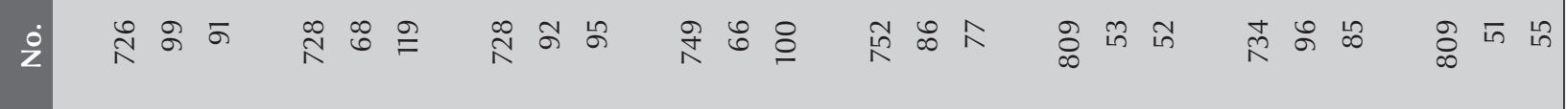

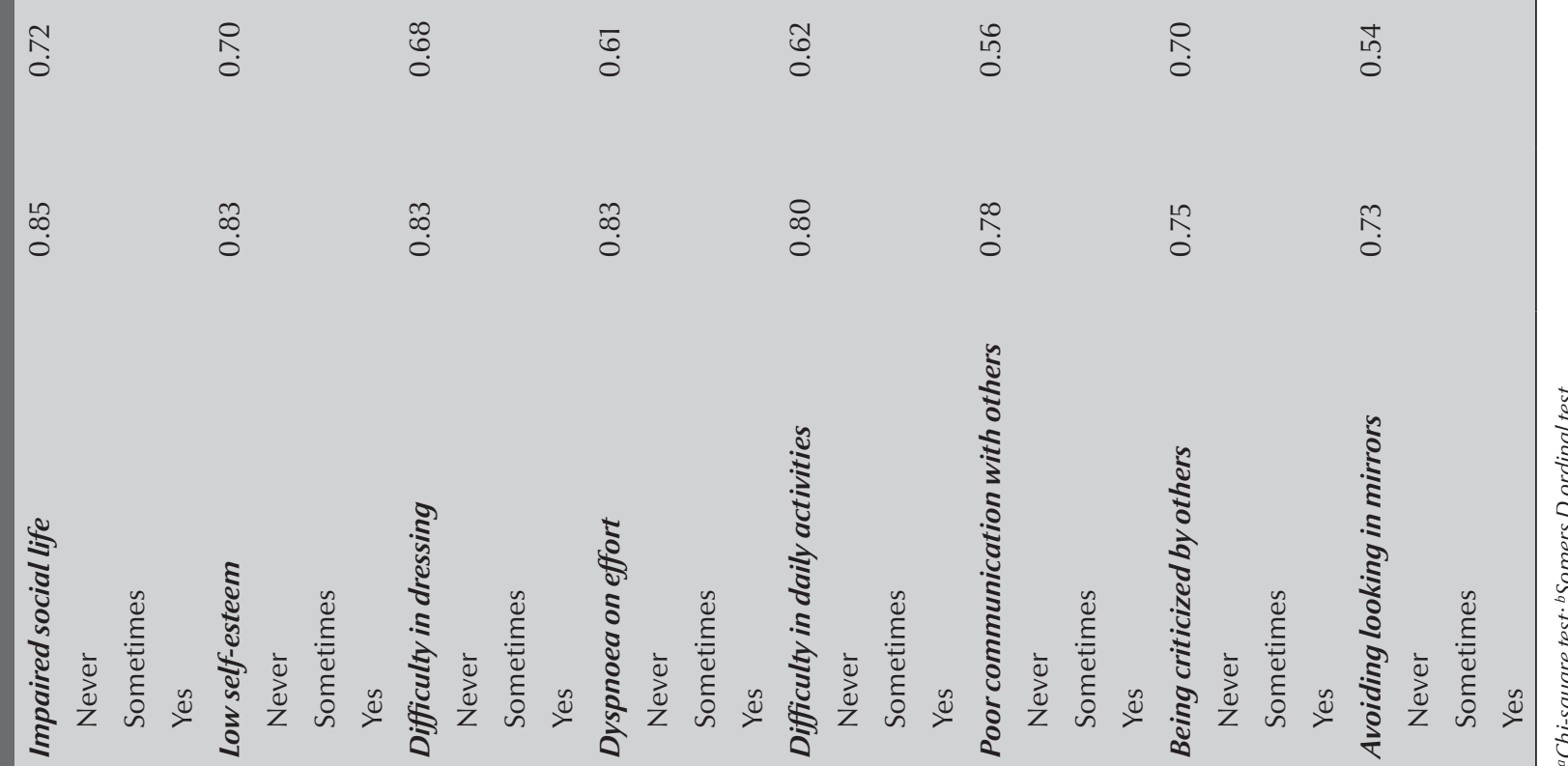




\begin{tabular}{|c|c|c|c|c|c|c|c|}
\hline \multirow[t]{3}{*}{ Variable } & \multicolumn{6}{|c|}{ Obesity distress score } & \multirow[b]{3}{*}{$P$-value } \\
\hline & \multicolumn{2}{|c|}{ Total } & \multicolumn{2}{|c|}{ Males } & \multicolumn{2}{|c|}{ Females } & \\
\hline & No. & Mean (SD) & No. & Mean (SD) & No. & Mean (SD) & \\
\hline Total & 1904 & $12.9(4.7)$ & 947 & $12.6(4.7)$ & 957 & $13.1(4.7)$ & $0.002^{\mathrm{a}}$ \\
\hline Normal weight & 1283 & $12.6(4.8)$ & 547 & $12.4(4.8)$ & 736 & $12.8(4.8)$ & $0.068^{\mathrm{a}}$ \\
\hline At-risk of obesity & 518 & $13.2(4.5)$ & 332 & $12.7(4.5)$ & 186 & $14.1(4.3)$ & $<0.00^{\mathrm{a}}$ \\
\hline Obese & 103 & $14.7(4.7)$ & 68 & $13.8(4.5)$ & 35 & $16.4(4.5)$ & $0.005^{\mathrm{a}}$ \\
\hline$P$-value & & $<0.001^{\mathrm{b}}$ & & & & & \\
\hline
\end{tabular}

${ }^{a}$ Wilcoxon test; ${ }^{b}$ Kruskal-Wallis test.

$S D=$ standard deviation .

boys, both among the whole sample and within the same category of BMI status. Moreover, in the multivariate analysis, sex was retained in the model as an independent factor of obesity-related distress. Besides obesity itself, weight dissatisfaction was another determinant of obesity-related distress.
This exploratory study showed that boys were more frequently overweight and obese than girls. Prevalence and gender differences in obesity and risk

\begin{tabular}{|c|c|c|c|c|c|c|c|}
\hline \multirow[t]{2}{*}{ Characteristic } & \multirow{2}{*}{$\begin{array}{l}\text { Obesity distress } \\
\text { score } \\
\text { Mean (SD) }\end{array}$} & \multirow[t]{2}{*}{$P$-value ${ }^{a}$} & \multicolumn{2}{|c|}{$\begin{array}{l}\text { Non-distressed } \\
\quad(n=920)\end{array}$} & \multicolumn{2}{|c|}{$\begin{array}{l}\text { Distressed } \\
(n=1013)\end{array}$} & \multirow[t]{2}{*}{$P$-value } \\
\hline & & & No. & $\%$ & No. & $\%$ & \\
\hline Region & & $<0.001$ & & & & & $<0.001^{\mathrm{b}}$ \\
\hline Bekaa & $14.0(4.7)$ & & 95 & 34.8 & 178 & 65.2 & \\
\hline Mount Lebanon & $12.5(4.4)$ & & 408 & 50.7 & 396 & 49.3 & \\
\hline North Lebanon & $12.9(5.3)$ & & 186 & 51.4 & 176 & 48.6 & \\
\hline South Lebanon & $12.9(4.8)$ & & 116 & 48.3 & 124 & 51.7 & \\
\hline Beirut & $13.0(4.6)$ & & 115 & 45.3 & 139 & 54.7 & \\
\hline Age (years) & & 0.695 & & & & & $0.736^{c}$ \\
\hline$<15$ & $13.0(4.7)$ & & 265 & 46.7 & 302 & 53.3 & \\
\hline $15-16$ & $12.9(4.7)$ & & 358 & 47.1 & 402 & 52.9 & \\
\hline$>16$ & $12.8(4.7)$ & & 295 & 48.8 & 309 & 51.2 & \\
\hline Has disease favouring obesity & & $<0.001$ & & & & & $0.001^{\mathrm{b}}$ \\
\hline Yes & $15.2(5.0)$ & & 14 & 25.0 & 42 & 75.0 & \\
\hline No & $12.8(4.7)$ & & 904 & 48.2 & 971 & 51.8 & \\
\hline $\begin{array}{l}\text { Obese persons in the family } \\
\text { (no.) }\end{array}$ & & $<0.001$ & & & & & $<0.001^{\mathrm{c}}$ \\
\hline 0 & $12.4(4.6)$ & & 612 & 52.5 & 554 & 47.5 & \\
\hline $1-2$ & $13.5(4.8)$ & & 253 & 42.2 & 347 & 57.8 & \\
\hline$>2$ & $14.0(4.5)$ & & 55 & 32.9 & 112 & 67.1 & \\
\hline $\begin{array}{l}\text { History of obesity during } \\
\text { childhood }\end{array}$ & & $<0.001$ & & & & & $<0.001^{\mathrm{b}}$ \\
\hline Yes & $14.0(4.8)$ & & 155 & 36.7 & 267 & 63.3 & \\
\hline No & $12.6(4.7)$ & & 763 & 50.6 & 746 & 49.4 & \\
\hline Satisfied with own weight & & $<0.001$ & & & & & $<0.001^{\mathrm{c}}$ \\
\hline Not at all & $14.3(4.6)$ & & 154 & 31.0 & 343 & 69.0 & \\
\hline More or less & $12.7(4.6)$ & & 305 & 49.8 & 307 & 50.2 & \\
\hline Yes & $12.1(4.7)$ & & 461 & 56.0 & 362 & 44.0 & \\
\hline
\end{tabular}

${ }^{a}$ Kruskal-Wallis or Wilcoxon tests; ${ }^{b}$ Chi-squared test; ' ${ }^{c}$ Somers ${ }^{\prime} D$ test. $S D=$ standard deviation . 


\begin{tabular}{|c|c|c|c|c|c|c|c|}
\hline \multirow[t]{2}{*}{ Food consumption } & \multirow{2}{*}{$\begin{array}{l}\text { Obesity distress } \\
\text { score } \\
\text { Mean (SD) }\end{array}$} & \multirow[t]{2}{*}{$P$-value ${ }^{a}$} & \multicolumn{2}{|c|}{$\begin{array}{l}\text { Non-distressed } \\
(n=920)\end{array}$} & \multicolumn{2}{|c|}{$\begin{array}{l}\text { Distressed } \\
(n=1013)\end{array}$} & \multirow[t]{2}{*}{$P$-value ${ }^{b}$} \\
\hline & & & No. & $\%$ & No. & $\%$ & \\
\hline Fast food (times/week) & & 0.39 & & & & & 0.33 \\
\hline 0 & $12.5(4.5)$ & & 40 & 4.3 & 40 & 3.9 & \\
\hline $1-3$ & $12.8(4.7)$ & & 651 & 70.8 & 703 & 69.4 & \\
\hline $4-7$ & $13.1(4.9)$ & & 225 & 24.5 & 263 & 26.0 & \\
\hline$>7$ & $14.8(5.2)$ & & 4 & 0.4 & 7 & 0.7 & \\
\hline Lebanese dishes (times/week) & & 0.44 & & & & & 0.05 \\
\hline 0 & $12.5(4.9)$ & & 77 & 8.4 & 63 & 6.2 & \\
\hline $1-3$ & $12.8(4.6)$ & & 470 & 51.1 & 501 & 49.5 & \\
\hline $4-7$ & $13.1(4.8)$ & & 366 & 39.8 & 445 & 43.9 & \\
\hline$>7$ & $11.6(4.1)$ & & 7 & 0.8 & 4 & 0.4 & \\
\hline Fruit juice (times/week) & & 0.11 & & & & & 0.71 \\
\hline 0 & $12.6(4.7)$ & & 63 & 6.9 & 62 & 6.1 & \\
\hline $1-3$ & $12.8(4.6)$ & & 439 & 47.8 & 500 & 49.4 & \\
\hline $4-7$ & $13.1(4.8)$ & & 406 & 44.2 & 448 & 44.3 & \\
\hline$>7$ & $10.0(2.3)$ & & 11 & 1.2 & 2 & 0.2 & \\
\hline Soft drinks (times/week) & & 0.03 & & & & & 0.11 \\
\hline 0 & $12.1(4.8)$ & & 94 & 10.2 & 64 & 6.3 & \\
\hline $1-3$ & $12.8(4.7)$ & & 381 & 41.5 & 435 & 42.9 & \\
\hline $4-7$ & $13.1(4.8)$ & & 429 & 46.7 & 504 & 49.8 & \\
\hline$>7$ & $11.9(4.3)$ & & 15 & 1.6 & 10 & 1.0 & \\
\hline $\begin{array}{l}\text { Milk and dairy products } \\
\text { (times/week) }\end{array}$ & & 0.37 & & & & & 0.05 \\
\hline 0 & $12.5(5.1)$ & & 127 & 13.8 & 94 & 9.3 & \\
\hline $1-3$ & $13.0(4.7)$ & & 308 & 33.5 & 359 & 35.5 & \\
\hline $4-7$ & $12.9(4.7)$ & & 478 & 52.0 & 545 & 53.9 & \\
\hline$>7$ & $13.9(5.0)$ & & 7 & 0.8 & 14 & 1.4 & \\
\hline $\begin{array}{l}\text { Sweets and candies } \\
\text { (times/week) }\end{array}$ & & 0.28 & & & & & 0.57 \\
\hline 0 & $12.5(4.7)$ & & 38 & 4.1 & 36 & 3.6 & \\
\hline $1-3$ & $12.9(4.7)$ & & 380 & 41.3 & 407 & 40.3 & \\
\hline $4-7$ & $13.0(4.7)$ & & 487 & 53.0 & 562 & 55.6 & \\
\hline$>7$ & $11.1(4.0)$ & & 14 & 1.5 & 6 & 0.6 & \\
\hline $\begin{array}{l}\text { Potato chips and popcorn } \\
\text { (times/week) }\end{array}$ & & $<0.001$ & & & & & 0.006 \\
\hline 0 & $12.6(4.7)$ & & 57 & 6.2 & 51 & 5.0 & \\
\hline $1-3$ & $12.5(4.6)$ & & 471 & 51.3 & 462 & 45.6 & \\
\hline $4-7$ & $13.4(4.9)$ & & 378 & 41.1 & 497 & 49.1 & \\
\hline$>7$ & $10.1(2.6)$ & & 13 & 1.4 & 3 & 0.3 & \\
\hline $\begin{array}{l}\text { Vegetables and fruits } \\
\text { (times/week) }\end{array}$ & & 0.18 & & & & & 0.017 \\
\hline 0 & $11.8(4.5)$ & & 48 & 5.2 & 32 & 3.2 & \\
\hline $1-3$ & $12.9(4.8)$ & & 251 & 27.3 & 254 & 25.1 & \\
\hline $4-7$ & $13.0(4.7)$ & & 613 & 66.6 & 712 & 70.3 & \\
\hline$>7$ & $13.1(4.1)$ & & 8 & 0.9 & 15 & 1.5 & \\
\hline
\end{tabular}

${ }^{a}$ Kruskal-Wallis test; ${ }^{b}$ Somers' $D$ test. $S D=$ standard deviation . 


\begin{tabular}{|c|c|c|c|c|c|c|c|}
\hline \multirow[t]{2}{*}{ Eating and dieting habits } & \multirow{2}{*}{$\begin{array}{l}\text { Obesity distress } \\
\text { score } \\
\text { Mean (SD) }\end{array}$} & \multirow[t]{2}{*}{$P$-value ${ }^{\mathrm{a}}$} & \multicolumn{2}{|c|}{$\begin{array}{l}\text { Non-distressed } \\
\quad(n=920)\end{array}$} & \multicolumn{2}{|c|}{$\begin{array}{l}\text { Distressed } \\
(n=1013)\end{array}$} & \multirow[t]{2}{*}{$P$-value ${ }^{\mathrm{b}}$} \\
\hline & & & No. & $\%$ & No. & $\%$ & \\
\hline \multicolumn{8}{|l|}{ Speed of eating } \\
\hline Eats slowly & $12.8(4.7)$ & 0.51 & 459 & 49.9 & 476 & 47.0 & 0.20 \\
\hline Eats rapidly & $12.9(4.7)$ & & 461 & 50.1 & 537 & 53.0 & \\
\hline \multicolumn{8}{|l|}{ Seeks to eat light food } \\
\hline Never & $12.2(4.7)$ & $<0.001$ & 568 & 61.9 & 460 & 45.4 & $<0.001$ \\
\hline Sometimes & $13.4(4.9)$ & & 232 & 25.3 & 343 & 33.9 & \\
\hline Always & $14.2(4.9)$ & & 118 & 12.9 & 210 & 20.7 & \\
\hline \multicolumn{8}{|l|}{ Tries to empty his dish } \\
\hline No & $12.8(4.9)$ & 0.33 & 194 & 21.1 & 201 & 19.9 & 0.51 \\
\hline Yes & $12.9(4.7)$ & & 725 & 78.9 & 809 & 80.1 & \\
\hline Tries to count calories & & $<0.001$ & & & & & 0.016 \\
\hline Yes & $13.5(4.9)$ & & 225 & 24.5 & 297 & 29.3 & \\
\hline No & $12.7(4.6)$ & & 695 & 75.5 & 715 & 70.7 & \\
\hline Tries to empty his/her plate & & 0.63 & & & & & 0.51 \\
\hline Yes & $12.9(4.7)$ & & 194 & 21.1 & 201 & 19.9 & \\
\hline No & $12.8(4.9)$ & & 725 & 78.9 & 809 & 80.1 & \\
\hline $\begin{array}{l}\text { Encouraged by the media to } \\
\text { eat food }\end{array}$ & & $<0.001$ & & & & & $<0.001$ \\
\hline Yes & $13.4(4.8)$ & & 433 & 47.2 & 592 & 58.4 & \\
\hline No & $12.3(4.5)$ & & 485 & 52.8 & 421 & 41.6 & \\
\hline Likes to eat between meals & & 0.136 & & & & & 0.285 \\
\hline Never & $12.5(4.9)$ & & 171 & 18.6 & 161 & 15.9 & \\
\hline Sometimes & $12.9(4.4)$ & & 332 & 36.1 & 381 & 37.6 & \\
\hline Always & $13.1(4.9)$ & & 416 & 45.3 & 471 & 46.5 & \\
\hline \multicolumn{8}{|l|}{$\begin{array}{l}\text { Eats when psychologically } \\
\text { distressed }\end{array}$} \\
\hline No & $12.3(4.5)$ & $<0.001$ & 650 & 70.7 & 562 & 55.5 & $<0.001$ \\
\hline Yes & $13.9(4.8)$ & & 270 & 29.3 & 450 & 44.5 & \\
\hline \multicolumn{8}{|l|}{ Ever been on weight-loss diet } \\
\hline No & $12.5(4.6)$ & $<0.001$ & 769 & 84.0 & 708 & 70.0 & $<0.001$ \\
\hline Yes & $14.3(4.7)$ & & 147 & 16.0 & 303 & 30.0 & \\
\hline \multicolumn{8}{|l|}{ Ever taken drugs to lose weight } \\
\hline No & $12.8(4.7)$ & $<0.001$ & 893 & 97.7 & 963 & 95.3 & 0.003 \\
\hline Yes & $14.9(5.1)$ & & 21 & 2.3 & 48 & 4.7 & \\
\hline \multicolumn{8}{|l|}{ Urged by media to lose weight } \\
\hline No & $12.0(4.4)$ & $<0.001$ & 649 & 70.7 & 511 & 50.5 & $<0.001$ \\
\hline Yes & $14.2(4.9)$ & & 269 & 29.3 & 501 & 49.5 & \\
\hline Urged by family to lose weight & & $<0.001$ & & & & & $<0.001$ \\
\hline No & $12.2(4.7)$ & & 734 & 80.0 & 588 & 58.3 & \\
\hline Yes & $14.4(4.4)$ & & 184 & 20.0 & 421 & 41.7 & \\
\hline
\end{tabular}

${ }^{a}$ Kruskal-Wallis test; ${ }^{b}$ chi-squared test.

$S D=$ standard deviation .

of obesity are in accordance with the re- adolescents $[9,10,35]$ and among States [36] and Taiwan and Fu-Chien sults from previous studies in Lebanese children and adolescents in the United [37]. 


\begin{tabular}{|c|c|c|c|c|c|c|c|}
\hline \multirow[t]{2}{*}{ Physical activity } & \multirow{2}{*}{$\begin{array}{l}\text { Obesity distress } \\
\text { score } \\
\text { Mean (SD) }\end{array}$} & \multirow[t]{2}{*}{$P$-value ${ }^{a}$} & \multicolumn{2}{|c|}{$\begin{array}{l}\text { Non-distressed } \\
\quad(n=920)\end{array}$} & \multicolumn{2}{|c|}{$\begin{array}{l}\text { Distressed } \\
(n=1013)\end{array}$} & \multirow[t]{2}{*}{$P$-value ${ }^{\mathrm{b}}$} \\
\hline & & & No. & $\%$ & No. & $\%$ & \\
\hline Television watching (hours per day) & & 0.56 & & & & & 0.33 \\
\hline $1-3$ & $12.8(4.7)$ & & 540 & 59.4 & 571 & 57.2 & \\
\hline$>3$ & $13.9(4.7)$ & & 369 & 40.6 & 427 & 42.8 & \\
\hline Sports frequency (times per week) & & 0.33 & & & & & 0.009 \\
\hline 0 & $13.1(4.8)$ & & 206 & 22.6 & 254 & 25.3 & \\
\hline $1-3$ & $12.8(4.7)$ & & 498 & 54.4 & 545 & 54.3 & \\
\hline$>4$ & $12.7(4.5)$ & & 209 & 22.9 & 205 & 20.4 & \\
\hline \multicolumn{8}{|l|}{ Sports (hours per week) } \\
\hline 0 & $13.1(4.8)$ & 0.45 & 206 & 22.9 & 255 & 25.5 & 0.02 \\
\hline $1-2$ & $12.7(4.6)$ & & 214 & 23.8 & 270 & 27.0 & \\
\hline $3-6$ & $13.6(5.0)$ & & 281 & 31.2 & 287 & 28.7 & \\
\hline$>6$ & $12.4(4.2)$ & & 199 & 22.1 & 188 & 18.8 & \\
\hline Physical activity level & Median (IQR) & & No. & $\%$ & No. & $\%$ & \\
\hline None & $13.1(4.8)$ & 0.28 & 206 & 22.9 & 255 & 25.5 & 0.06 \\
\hline Low & $12.9(4.7)$ & & 311 & 34.6 & 354 & 35.4 & \\
\hline Moderate & $13.0(4.8)$ & & 184 & 20.4 & 201 & 20.1 & \\
\hline Vigorous & $12.4(4.4)$ & & 199 & 22.1 & 190 & 19.0 & \\
\hline
\end{tabular}

${ }^{a}$ Kruskal-Wallis test; ${ }^{b}$ Somers' $D$ test.

$S D=$ standard deviation; $I Q R=$ interquartile range.

Despite these higher rates of obesity, boys were more satisfied than girls with their weight. This is similar to the results of other studies showing that even when not overweight, girls may be dissatisfied with their own weight and may suffer from obesity-related distress [38,39]. It is thus probable that media-generated feminine images, family and peer pressure for thinness and the fear of obesity are more marked in Lebanese girls than boys. Indeed it has been demonstrated that girls as young as 5 years of age care more than boys about their self-image and associate it with weight status [40].

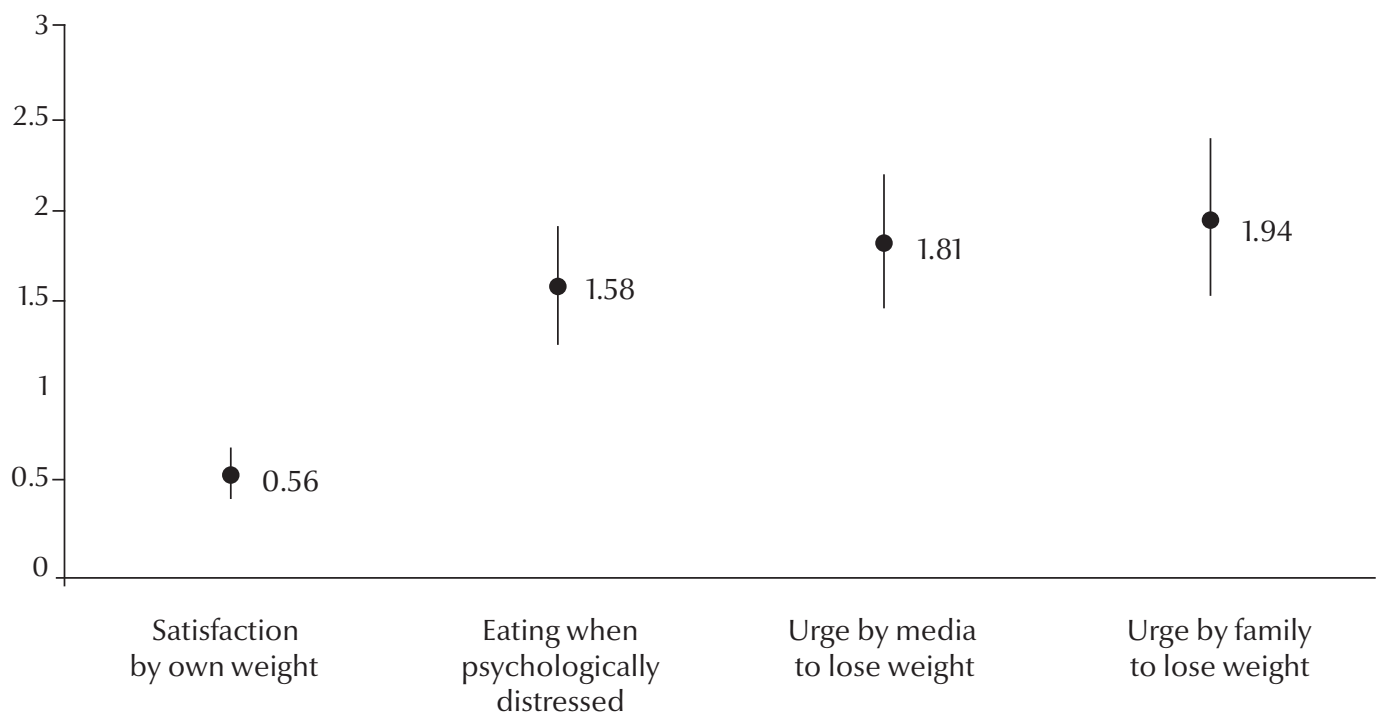

Figure 1 Multivariate analysis: significant determinants of obesity-related distress in Lebanese adolescents by stepwise backward logistic regression (adjusted odds ratios and 95\% confidence intervals shown) 
These findings reflect the dangers of psychological maladjustment and nutritional disorders [39]. Indeed, we found that obesity-related distress, particularly when related to family and media pressure to lose weight, increased the risk of using drastic weight-loss measures (e.g. dieting and taking drugs), but did not seem to be associated with healthy dietary habits or engagement in physical activity.

While prevention of obesity in adolescence is important, it should be performed according to international guidelines [41], through motivation to avoid obesity related-distress and its negative consequences [42]. While healthy eating and activity are together considered powerful tools against obesity [43], it has been shown that being forced to exercise during childhood has potentially negative consequences on willingness to engage in physical activities in later life [44]. Moreover, dieting and unhealthy weight-control behaviours also predict outcomes related to obesity and eating disorders many years later $[45,46]$, in addition to dietary inadequacy [47]. A shift away from dieting and drastic weight-control measures towards the long-term implementation of healthy eating and physical activity behaviour is needed to prevent obesity and eating disorders among adolescents.

Some points should be noted that might affect the validity of this study. Further studies are needed to confirm our results and to illuminate the complex behavioural patterns of adolescents from the sociological and psychological points of view.
The obesity distress scale that we constructed needs further validation, particularly test-retest reliability and convergent validity with other internationally used tests (e.g. the Individual Quality of Life (IQOL)-Lite [48] and the Impact of Weight on Quality of Life (IWQOL)-Kids [49]) scales. A confirmatory factor analysis also needs to be performed.

In conclusion, in this exploratory study, we reported the first scale that evaluated obesity-related distress in Lebanese adolescents. Family and media pressure to lose weight seemed particularly important in causing obesity-related distress. However, these factors did not seem to encourage individuals suffering from obesity-related distress into healthier eating patterns or engagement in physical activity.

\section{References}

1. Hadigan C. Pediatric and adolescent obesity. International Seminars in Pediatric Gastroenterology and Nutrition, 2001, 10:1-7.

2. Schwartz MB, Brownell KD. Obesity and body image. Body Image, 2004, 1:43-56.

3. Makara-Studzińska M, Zaborska A. Obesity and body image. Psychiatria Polska, 2009, 43:109-114.

4. Grilo $\mathrm{CM}$ et al. Teasing, body image, and self-esteem in a clinical sample of obese women. Addictive Behaviors, 1994, 19:443-450.

5. Schwimmer JB et al. Health-related quality of life of severely obese children and adolescents. Journal of the American Medical Association, 2003, 289:1813-1819.

6. Strauss RS. Childhood obesity and self-esteem. Pediatrics, 2000, 105:e15.

7. Cargill BR et al. Binge eating, body image, depression, and self-efficacy in an obese clinical population. Obesity Research, 1999, 7:379-386

8. Bacchini $D$ et al. Eating disorder variables and self image in Italian girls attending a weight control clinic. Eating and Weight Disorders, 2005, 10:125-132.

9. Chakar H, Salameh P. Courbes de croissance et prévalence de l'obésité chez les adolescents des écoles privées au Liban. [Growth and obesity in Lebanese private schools children]. Le Journal Medical Libanais, 2007, 55:75-82.

10. Chakar H, Salameh P. Obesity in Lebanese private schools adolescents. European Journal of Public Health, 2006, 60:2-7.

11. Food balance sheets 2009. FAOSTAT. Food and Agriculture Organization [website] (http://faostat.fao.org/site/368/default.aspx, accessed 13 November 2011).

12. Adair LS, Popkin BM. Are child eating patterns being transformed globally? Obesity Research, 2005, 13:1281-1299.

13. Ekelund $U$ et al. Physical activity but not energy expenditure is reduced in obese adolescents: a case-control study. American Journal of Clinical Nutrition, 2002, 76:935-941.
14. Sallis JF. Age-related decline in physical activity: a synthesis of human and animal studies. Medicine and Science in Sports and Exercise, 2000, 32:1598-1600.

15. Telama R, Yang X. Decline of physical activity from youth to young adulthood in Finland. Medicine and Science in Sports and Exercise, 2000, 32:1617-1622.

16. Trost SG et al. Age and gender differences in objectively measured physical activity in youth. Medicine and Science in Sports and Exercise, 2002, 34:350-355.

17. Sallis JF. Epidemiology of physical activity and fitness in children and adolescents. Critical Reviews in Food Science and Nutrition, 1993, 33:403-408.

18. Tanasescu M et al. Biobehavioral factors are associated with obesity in Puerto Rican children. Journal of Nutrition, 2000, 130:1734-1742.

19. Salameh P, Barbour B. Obesity associated behaviour in 1933 Lebanese adolescents. Lebanese Medical Journal, 2011, 59(4) [in press].

20. Magarey AM et al. Predicting obesity in early adulthood from childhood and parental obesity. International Journal of Obesity and Related Metabolic Disorders, 2003, 27:505513.

21. Luciano A et al. Definition of obesity in childhood: criteria and limits. Minerva Pediatrica, 2003, 55:453-459.

22. de Onis $\mathrm{M}$ et al. Development of a WHO growth reference for school-aged children and adolescents. Bulletin of the World Health Organization, 2007, 85:660-667.

23. Cole $\mathrm{T}$ et al. Establishing a standard definition for children overweight and obesity worldwide: international survey. British Medical Journal, 2000, 320:1240-1246.

24. Ainsworth BE et al. Compendium of physical activities: energy costs of human movement. Medicine and Science in Sports and Exercise, 1993, 25:71-80. 
25. Ainsworth BE et al. Compendium of physical activities: an update of activity codes and MET intensities. Medicine and Science in Sports and Exercise, 2000, 32(Suppl. 9):S498-S516.

26. Kriska AM, Casperson CJ. Introduction to a collection of physical activity questionnaires. Medicine and Science in Sports and Exercise, 1997, 29(Suppl. 6):S5-S9.

27. Kimm SY et al. Longitudinal changes in physical activity in a biracial cohort during adolescence. Medicine and Science in Sports and Exercise, 2000, 32:1445-1454.

28. Batal M, Hunter E. Traditional Lebanese dishes based on wild plants: an answer to diet simplification? Food and Nutrition Bulletin, 2007, 28:S303-S311.

29. Darmon $\mathrm{N}$ et al. Nutrient profiles discriminate between foods according to their contribution to nutritionally adequate diets: A validation study using linear programming and the SAIN, LIM system. American Journal of Clinical Nutrition, 2009, 89:1227-1236.

30. Issa $\mathrm{C}$ et al. The nutrient profile of traditional Lebanese composite dishes: comparison with composite dishes consumed in France. International Journal of Food Sciences and Nutrition, 2009, 60(Suppl. 4):S1-S10.

31. Zeller MH, Modi AC. Development and initial validation of an obesity-specific quality-of-life measure for children: sizing me up. Obesity, 2009, 17:1171-1177.

32. Kolotkin RL, Crosby RD. Psychometric evaluation of the impact of weight on quality of life-lite questionnaire (IWQOL-lite) in a community sample. Quality of Life Research, 2002, 11:157-171.

33. Kolotkin R et al. Development of a brief measure to assess quality of life in obesity. Obesity Research, 2001, 9:102-112.

34. Patrick D, Bushnell D, Rothman M. Performance of two selfreport measures for evaluating obesity and weight loss. Obesity Research, 2004, 12:48-58.

35. Sibai AM et al. Prevalence and covariates of obesity in Lebanon: findings from the first epidemiological study. Obesity Research, 2003, 11:1353-1361.

36. Styne D. Childhood and adolescent obesity. Prevalence and significance. Pediatric Clinics of North America, 2001, 48:1-4.

37. Huang YC, Wu JY, Yang MJ. Weight-for-height reference and the prevalence of obesity for school children and adolescents in Taiwan and Fuchien areas. Journal of the Chinese Medical Association, 2003, 66:599-606.
38. Vander Wal JS, Thelen MH. Eating and body image concerns among obese and average-weight children. Addictive Behaviors, 2000, 25:775-778.

39. De Sousa SM. Body-image and obesity in adolescence: a comparative study of social-demographic, psychological, and behavioral aspects. Spanish Journal of Psychology, 2008, 11:551-563.

40. Brown $\mathrm{M}$ et al. Obesity in children and adolescents. Clinics in Family Practice, 2002, 4:1-9.

41. Committee on Nutrition, American Academy of Pediatrics. Policy statement: prevention of pediatric overweight and obesity. Pediatrics, 2003, 112:424-430.

42. McWhorter JW, Wallmann H, Alpert P. The obese child: motivation as a tool for exercise. Journal of Pediatric Health Care, 2003, 17:11-17.

43. Gottesman MM. Healthy eating and activity together (heat): weapons against obesity. Journal of Pediatric Health Care, 2003, 17:210-215.

44. Taylor WC et al. Childhood and adolescent physical activity patterns and adult physical activity. Medicine and Science in Sports and Exercise, 1999, 31:118-123.

45. Neumark-Sztainer D et al. Obesity, disordered eating, and eating disorders in a longitudinal study of adolescents: how do dieters fare 5 years later? Journal of the American Dietetic Association, 2006, 106:559-568.

46. Field AE et al. Relation between dieting and weight change among preadolescents and adolescents. Pediatrics, 2003, 112:900-906.

47. Neumark-Sztainer D et al. Weight-control behaviors among adolescent girls and boys: implications for dietary intake. Journal of the American Dietetic Association, 2004, 104:913-920.

48. Forhan M, Vrkljan B, Macdermid J. A systematic review of the quality of psychometric evidence supporting the use of an obesity-specific quality of life measure for use with persons who have class III obesity. Obesity Reviews, 2010, 11:222-228.

49. Kolotkin RL et al. Assessing weight-related quality of life in adolescents. Obesity, 2006, 14:448-457. 